\title{
Effect of Saliva and Mucin-Based Saliva Substitutes on Fretting Processes of 316 Austenitic Stainless Steel
}

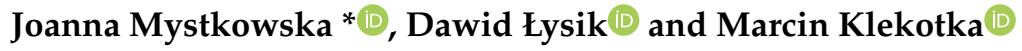 \\ Department of Materials Engineering and Production, Faculty of Mechanical Engineering, \\ Bialystok University of Technology, Wiejska 45C, 15-351 Bialystok, Poland; d.lysik@pb.edu.pl (D.Ł.); \\ m.klekotka@pb.edu.pl (M.K.) \\ * Correspondence: j.mystkowska@pb.edu.pl; Tel.: +48-571-443-083
}

Received: 31 December 2018; Accepted: 31 January 2019; Published: 2 February 2019

check for updates

\begin{abstract}
The paper presents the results of research of the fretting process of 316 austenitic stainless steel in the environment of natural saliva and mucin-based saliva preparations. The aim of the work was the evaluation of synthetic saliva preparations on biomaterial wear during fretting and fretting-corrosion. The fretting process, in the oscillatory micro-movements conditions, occurs in the joints of removable dentures, especially during the chewing phase. Fretting usually leads to the intensification of fatigue damage processes of materials. Experimental research, through rheological, fretting, fretting-corrosion, and microscopic analysis were performed. Tests indicate that natural saliva and saliva preparations are similar in terms of viscoelastic properties. The statistically significant proposed saliva solutions reduced the material wear in comparison to dry sliding, which is important in the case of people with saliva secretion problem. The addition of xanthan gum to the artificial saliva composition improved rheological characteristics, but on the other hand, led to an increase of secondary wear. It was confirmed by the volumetric wear of the samples and evaluation of energy dissipated during friction. Fretting-corrosion processes were explained by a mechanism related to crevice corrosion supported by friction.
\end{abstract}

Keywords: saliva; mucin; fretting wear; fretting-corrosion; austenitic stainless steel

\section{Introduction}

The loss of natural teeth impairs the functions of the tooth system, and disturbs chewing and speech. Then, there is the need to use implants and prosthetic restorations. In the group of materials used in dentistry, they are austenitic steels, which as one of the first materials were used for implantation in the human body. The Association of British Society of Pediatric Dentistry (BSPD) recommends this steel for use on prosthetic constructions, elements of orthodontic appliances, and dental implants [1]. The main alloying elements of austenitic steels are chromium, nickel, and molybdenum. The amount of silicon and manganese is increased, and in some cases, also nitrogen and niobium. Chromium content above $26 \%$ mas. and molybdenum in the amount of $3.3 \%$ mas. provides adequate resistance to pitting corrosion in the environment of tissues and body fluids [2,3].

Advances in many areas of medicine, also in dental prosthetics, depend to a large extent on the development of new materials and constructions as well as understanding the complex processes of their tissue adaptation. The associated friction and corrosion phenomena, in addition to the biofilm influence $[4,5]$, highly determine the durability and quality of prosthetic constructions, thus affecting the comfort of their use. Problems of friction and wear within the tooth system are clearly visible and raised in the literature [6], and also with respect to widely used removable dentures, mainly skeletal dentures, and overlay implant prostheses. In the tribological aspect, it should be emphasized that, in the oral cavity, there are intense friction processes between opposite teeth; teeth and dental fillings; 
elements of orthodontic appliances; and implants and elements of dental prosthetics. Particularly intensive friction and wear processes occur in the areas of denture fixation with the substrate, where the metal head of the implant rubs against metal clips in the prosthesis.

Taking into account metallic biomaterials that work in the body under variable load conditions in an electrochemically active environment, rubbing processes in fretting conditions, and the accompanying corrosion (so-called fretting-corrosion) are particularly undesirable [7-9]. The term fretting means a complex process of oscillatory micro-movements (on average in the range of 2-100 $\mu \mathrm{m}$ ) of two contacting surfaces, which in effect leads to the damage of the surface layers [10]. The mechanism of this phenomenon depends on several variables, which may include: The type of material; the amplitude of the slip; normal force or contact pressure; and microstructure and surface properties being in contact. This type of sliding, in the conditions of micro-movements, undoubtedly occurs in the joints of removable dentures, especially during the chewing phase and in the kinematic connections of orthodontic appliances (lock-splint). Fretting usually leads to the intensification of corrosion and fatigue failure processes of materials.

There is limited information about these processes of materials failure used in dental applications, especially in the oral environment. In the context of the degradation of prosthetic materials, the influence of saliva on friction and corrosion processes is significant $[3,11,12]$. The role of saliva as a biological lubricant in the bio-tribological tooth system is extremely important, although it is undiscovered and underestimated. Its secretion ensures proper hydration of the mucous membrane and the surface of biomaterials used in the oral cavity. Saliva plays a decisive role in chewing processes, and consequently in the wear of hard tooth tissues [13,14], dental fillings, biomaterials used in implantation, prosthetic, and orthodontic applications [15]. An important role in these processes, especially in boundary lubrication conditions, is attributed to the presence of organic components (mucin, statherin, lysozyme, lactoferrin, and immunoglobulin IgA) in natural saliva [16]. The MG1 type of mucin is in the form of oligomeric structure, whose large size and elongated form in combination with a hydrophilic sugar coat give the saliva a characteristic weak gel consistency $[17,18]$. This provides the saliva with proper viscosity as well as the proper degree of moisture in the oral tissues and reduces the friction force. Saliva covers the teeth, periodontium, tongue, and mucous membrane of the oral cavity with a thickness of 70-100 $\mu \mathrm{m}$, and on the hard palate with a film thickness below $10 \mu \mathrm{m}$ [19]. It also has a protective function on the surface of biomaterials [20].

The role of saliva is often underestimated until it decreased secretion is observed or its bio-functional properties are reduced. Intensification of biomaterials failure occurs particularly rapidly in the case of disturbances of salivary secretion through the salivary glands (the so-called xerostomia). The reason for this may be numerous drugs and diseases [21]. One of the most common methods for the treatment of salivary gland dysfunction is the use of artificial saliva. Research towards the search for natural salivary substitutes focus on the selection of ingredients that will favorably affect its bio-functional features, including tribological, rheological, and biological characteristics. Among the most used ingredients of artificial saliva, responsible for lubricating properties are carboxymethyl cellulose, hydroxyethyl cellulose, glycerin, cellulose gum, guar gum, and polymers [22]. Such substitute formulations in the form of so-called rinses, supports chewing processes, moisturizing the mouth, and performing biological functions of saliva. However, there are no substitutes for saliva that meet protection requirements with favorable tribological and anti-corrosive characteristics [23]. Taking this into account, in this work, salivary substitutes based on animal mucin and xanthan gum were proposed.

The subject of this study was the evaluation of the influence of saliva and mucin-based saliva substitutes on tribocorrosion processes (fretting, fretting-corrosion) of one of the most commonly used metallic biomaterial for dental applications: 316 austenitic stainless steel [2,24,25]. The extent, type of biomaterial damage, and an analysis of the chemical composition of sample surfaces after fretting were investigated. 
Analysis of the favorable lubricating properties of natural saliva indicates [26,27] that an important role in tribological processes, in addition to viscosity and chemical composition, can play the elastic properties of this fluid. In this context, the analysis of viscoelastic characteristics of saliva with respect to fretting wear processes of the tested biomaterial was performed.

\section{Materials and Methods}

Viscoelasticity, fretting, fretting-corrosion and corrosion tests were carried out in the environment of human natural saliva (S), mucin-based saliva preparation (M), and mucin and xanthan gum based saliva preparation (MX). Porcine gastric mucin was used to prepare saliva substitutes. All ingredients were purchased in Sigma-Aldrich (Saint Louis, MO, USA).

\subsection{Viscoelasticity-Oscillatory Rheology Tests}

The viscoelastic properties of saliva and mucin-based saliva preparations were carried out using Rheostress 6000 rheometer (Thermo Fisher Scientific, Waltham, MA, USA) at room temperature $\left(21 \pm 2{ }^{\circ} \mathrm{C}\right)$. The measurements were realized in a parallel plate system (Figure 1a) where the diameter of upper plate was $60 \mathrm{~mm}$ and the gap between plates was $1 \mathrm{~mm}$. Shear forces were applied by rotating the top plate in a parallel direction to the sample. Through the oscillating rotational motion of the upper plate, shear forces were applied to the sample, which caused the assumed deformation (Equation (1)) (shear strain amplitude ( $\left.\gamma_{0}\right)$ from 0.01 to 100). The torque used for this movement was measured, which made it possible to determine the shear stress $\tau$ and finally the modulus of elasticity $\left(G^{\prime}\right)$ and viscosity $\left(G^{\prime \prime}\right)$ (Equation (2)). The frequency $(f=2 \pi / \omega)$ of oscillations was $0.8 \mathrm{~Hz}$.

$$
\begin{gathered}
\gamma(t)=\gamma_{0} \sin (\omega t) \\
\tau(t)=G^{\prime} \gamma_{0} \sin (\omega t)+G^{\prime \prime} \gamma_{0} \cos (\omega t)
\end{gathered}
$$

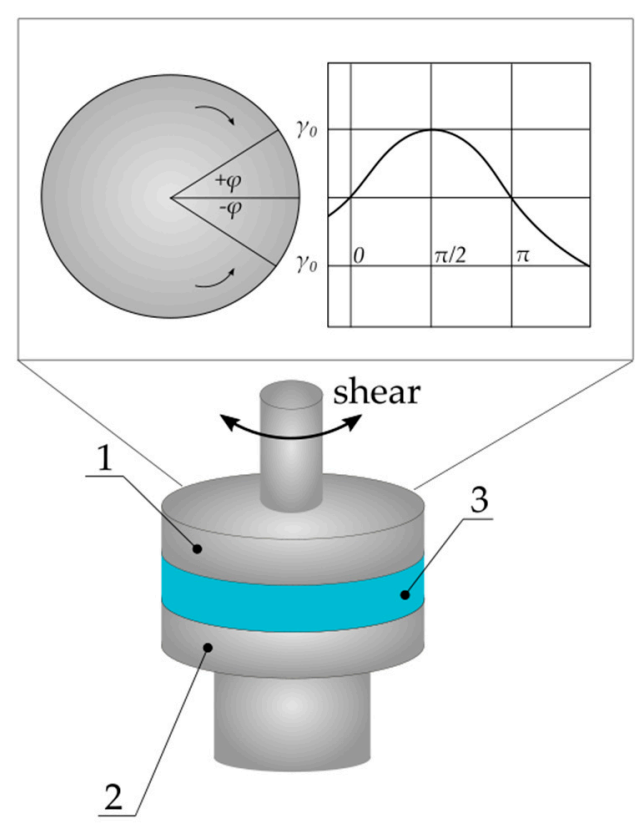

(a)

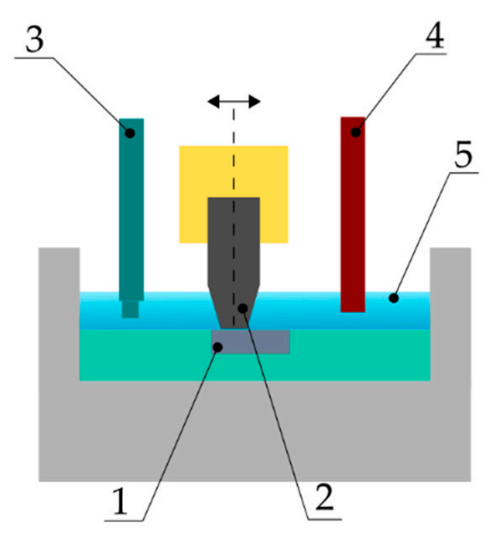

(b)

Figure 1. Schemes of used measuring systems: (a) Rheometer parallel plate system (1-upper movable plate, 2-bottom fixed plate, 3-sample); and (b) system for fretting-corrosion tests (1-sample (disc), 2-counter-sample (pin), 3-platinum electrode, 4-saturated calomel electrode, and 5-saliva environment). 


\subsection{Fretting and Fretting-Corrosion Tests}

In experimental investigations of fretting, fretting-corrosion, and corrosion, samples made of 316 implant steel with the composition given in Table 1 were tested. Fretting, fretting-corrosion and corrosion tests were performed at room temperature $\left(21 \pm 2{ }^{\circ} \mathrm{C}\right)$. Tribological tests were carried out by a pin-on-disc tester (designed and constructed at the Department of Materials Science and Production at the Faculty of Mechanical Engineering, Bialystok University of Technology, Bialystok, Poland), in accordance with the methodology described in [3]. In the fretting-corrosion tests, the VoltaLab 21 electrochemical research equipment (Radiometer Analytical, Lyon, France) was connected to the tribometer. The tribological pair (Figure 1b) consisted of a pin (counter-sample with a diameter of $6 \mathrm{~mm}$ ) terminated with a truncated cone with a beveled surface of about $1.33 \mathrm{~mm}^{2}$ and a disk (sample) with a diameter of $8 \mathrm{~mm}$, thickness $5 \mathrm{~mm}$, and roughness $R_{a}=0.4 \mathrm{~mm}$. Prior to testing, samples and counter samples were thoroughly cleaned in ethanol and then deionized water using an ultrasonic bath.

Table 1. Chemical composition of the 316 austenitic stainless steel used in this study (\%mas.).

\begin{tabular}{cccccc}
\hline Fe & Cr & Ni & Mo & Mn & Other \\
\hline 60.3 & 17.7 & 13.6 & 2.4 & 1.9 & 4.1 \\
\hline
\end{tabular}

The sample for the test was placed in a specially designed holder, where one flat surface of the sample had contact with the electrolyte. The sample was mounted on the movable stage of the device performing a reciprocal movement. The counter-sample was pressed against the surface of the disc (contact type: Flat on flat) at averaged unit pressure $p=15 \mathrm{MPa}$ (normal force equals to $19.95 \mathrm{~N}$ ). Fretting processes were carried out with small displacements (in the order of $100 \mu \mathrm{m}$ ) and frequency $f=0.8 \mathrm{~Hz}$, as in rheological tests. Assumed values of pressure and frequency were related to the conditions in the oral cavity during chewing, as described by Heintze [28]. During the test, the friction force (tangential force) $\mathrm{T}$ was measured by strain gauges, on the basis of which the coefficient of friction was determined $\left(\mu=T / F_{N}\right)$. At the first stage samples were lapped, resistance of movement increased, and then stabilized. After one hour of sliding, the stable values of friction coefficient were registered and statistical analysis was carried out. The duration of one fretting test (with simultaneous Open Circuit Potential measurements, see Section 2.2.1) was $3 \mathrm{~h}$ ( 3 stages: $1 \mathrm{~h}$ conditioning of the sample immersed in the solution; $1 \mathrm{~h}$ of sliding under fretting conditions- 4500 cycles; $1 \mathrm{~h}$ of OCP stabilization). The experiment was repeated three times for one saliva substitute. Corrosion measurements in fretting conditions were conducted in a three-electrode system, the diagram of which is shown in Figure $1 \mathrm{~b}$. The working electrode was a kinematic pair: Steel 316-steel 316, the reference electrode-saturated calomel electrode $\mathrm{Hg} / \mathrm{Hg}_{2} \mathrm{Cl}_{2} / \mathrm{Cl}^{-}$REF421 (Radiometer Analytical, Loveland, $\mathrm{CO}, \mathrm{USA}$ ), which the relative potential to a normal hydrogen electrode was +0.24 Volts. The auxiliary electrode was a platinum electrode XM140 (Radiometer Analytical, Loveland, CO, USA) with an area of $128 \mathrm{~mm}^{2}$. In addition to the Open Circuit Potential $\left(E_{O C P}\right)$ measurement, potentiodynamic tests were carried out (see Section 2.2.2).

After the tests, the surfaces of the samples were observed using a confocal laser scanning microscope (CLSM) LEXT OLS 4000 (Olympus, Tokyo, Japan) and scanning electron microscope (SEM) S-3000N (Hitachi, Tokyo, Japan) equipped with an EDS attachment for X-ray microanalysis. The evaluation of fretting wear and defects in the material after corrosion was carried out by measuring the volume of material loss using the CLSM technique [29]. This method allows determining the volume of voids and excess material deposited on the surface during friction. 


\subsubsection{Open Circuit Potential $\left(E_{O C P}\right)$}

Open Circuit Potential $\left(E_{O C P}\right)$ research was carried out in three stages. Samples were immersed in the electrolyte and changes in potential were recorded as a function of time. The first stage included measurements in static conditions, the second in the conditions of friction at a given load, and the third after the end of friction. To enable the relative stabilization of the measured values, each stage lasted for $1 \mathrm{~h}$.

\subsubsection{Potentiodynamic Test}

Corrosion tests using the potentiodynamic method in fretting conditions were carried out in two stages. In the first trial, the assessment of the resistance of the implant steel to pitting corrosion in the saliva environment under static conditions (without friction) was performed. In the second test, the corrosion resistance of the material during fretting was evaluated.

In order to stabilize the potential in potentiodynamic studies, samples were immersed in the electrolyte for $2 \mathrm{~h}$ before the test. The process of polarization under fretting conditions was started from the initial potential of $E_{\text {init. }}=E_{O C P}-100 \mathrm{mV}$. The potential change occurred in the anodic direction at a rate of $3 \mathrm{mV} / \mathrm{s}$. After reaching the maximum value of the measuring range $+4094 \mathrm{mV}$ (vs $\mathrm{Hg} / \mathrm{Hg}_{2} \mathrm{Cl}_{2} / \mathrm{Cl}^{-}$) or obtaining the anode current density of $1 \mathrm{~mA} / \mathrm{cm}^{2}$, the polarization direction was changed. In corrosion tests, the Open Circuit Potential $\left(E_{O C P}\right)$, corrosion potential $\left(E_{c o r}\right)$ and polarization resistance $\left(R_{p}\right)$ were recorded. The value of the polarization resistance was determined using the Stern method, analyzing the range $\pm 10 \mathrm{mV}$ in relation to the corrosive potential due to the need to maintain a linear relationship between the current density and the sample potential.

\section{Results and Discussion}

\subsection{Viscoelasticity}

In all bio-tribological systems, the viscoelasticity of the lubricant plays a key role in reducing movement resistance and wear of tissues and biomaterials [30]. In the oral cavity, where the lubricant is saliva, this property is determined by the presence of mucins that combine with each other at different intermolecular levels to form a weak gel structure $[17,27]$. Studies have shown that purified porcine gastric mucin can form similar structures to human mucins [31]. Additionally, in order to obtain a structure rheologically close to natural saliva, xanthan gum was used. Oscillatory rheology tests were carried out to determine the values of $G^{\prime}$ and $G^{\prime \prime}$ modulus as a function of shear strain. Results are shown in Figure 2.

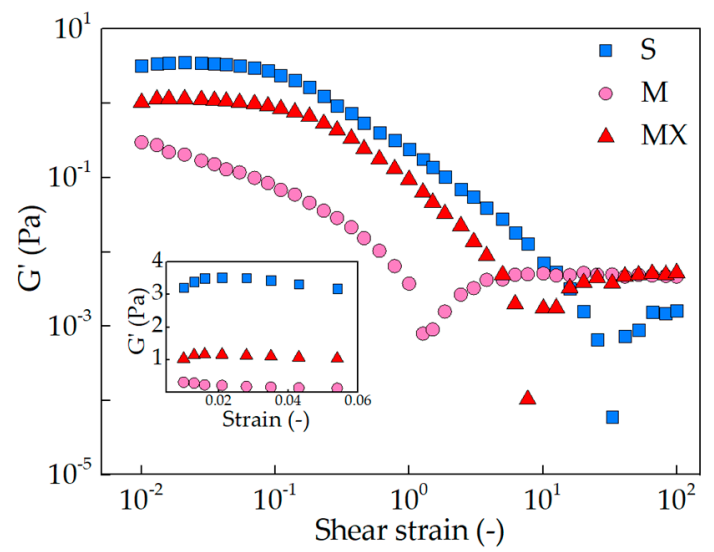

(a)

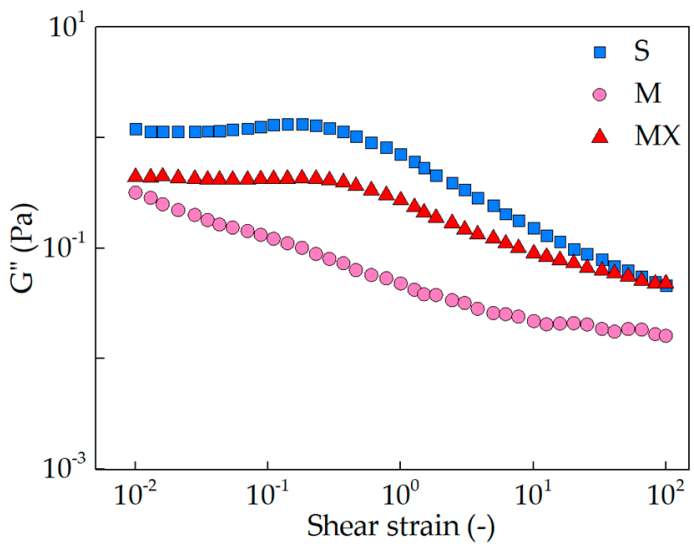

(b)

Figure 2. Viscoelasticity of saliva and mucin-based saliva preparations: (a) Elastic moduli $G^{\prime}$ in function of shear strain; and (b) viscous moduli $G^{\prime \prime}$ in function of shear strain. 
In conditions of low deformations, which were used during fretting, a linear viscoelasticity of the tested substances was observed. The elastic moduli $G^{\prime}$ values observed for natural saliva $(\sim 3.5 \mathrm{~Pa})$ were higher than for mucin-based saliva preparations ( 1 Pa for MX and $\sim 0.2-0.3$ for $\mathrm{M}$ ). The increase in deformations leads to a transition to the non-linear viscoelasticity and decrease in the values of the modulus $G^{\prime}$ and $G^{\prime \prime}$. The phenomenon of shear softening results from the reorganization of the structure, the orientation of macromolecules and the formation of shear planes [32]. At the shear strain limit ( 10 for $\mathrm{M}, \sim 1$ for $\mathrm{MX}$ and $\sim 50$ for $S$ ) the values of the $G^{\prime}$ moduli increase. It is related to shear stiffening and the probable mechanism results from the aggregation of macromolecules due to mechanical stresses [33]. Interestingly, to certain deformation values ( $150 \%$ of shear strain limit), these curves were reversible, which may indicate the reconstruction of the structure.

Both, natural saliva and mucin-based saliva preparations have viscoelastic properties. The obtained values of modulus $G^{\prime}$ and $G^{\prime \prime}$, in the whole range of studied strains, are higher for natural saliva than for synthetic preparations, while the character of the curves are similar.

\subsection{Fretting}

In the first stage of the wear research, tribological tests in fretting conditions were carried out for three different saliva environments: $S, M, M X$ and compared with results for dry friction (DF). On the basis of the obtained test results, friction coefficients, and volumetric wear were determined. SEM microscopic observations and chemical composition tests were performed to evaluate the surface after the fretting process.

Changes of the friction coefficient values over time for tribological pairs of austenitic stainless steel were presented in Figure 3a. The average values of friction coefficient were shown in Figure $3 b$. Results show statistically significant lower values of the tested parameter for human saliva $(\mu=0.19$, $\bullet \bullet p<0.001)$, preparations $\mathrm{M}(\mu=0.24, \bullet p<0.01)$, and $\mathrm{MX}(\mu=0.27, \bullet \bullet<0.01)$ in relation to dry friction $(\mu=0.39)$. On the other hand, the coefficient of friction in the environment of preparation MX was statistically significant higher $\left({ }^{*} p<0.05\right)$ in reference to natural saliva. The comparison of tested artificial saliva substitutes shows that lower resistance of movement was observed for saliva preparation based on mucin $(\mathrm{M})$, which formed protective lubricating layers. The presence of such layer prevents direct contact of metal surfaces of the kinematic pair, as was confirmed for typical friction $[3,20]$.

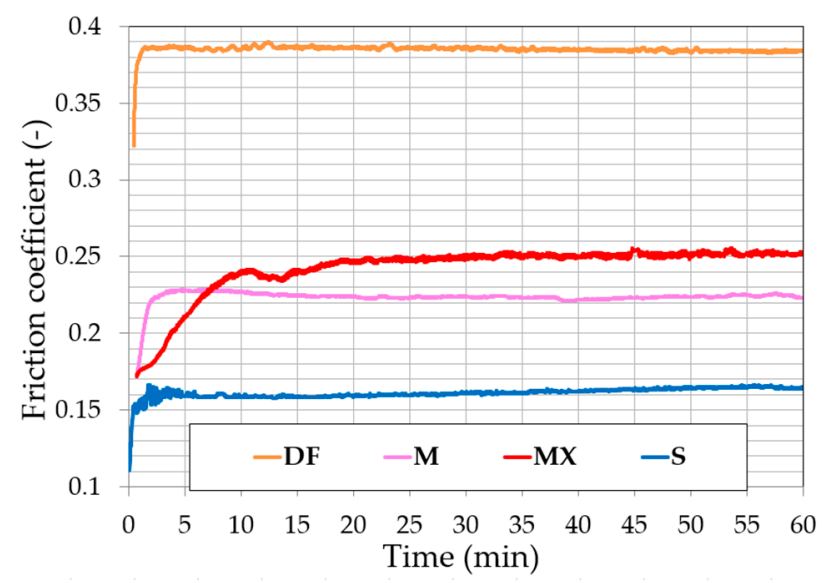

(a)

Figure 3. Cont. 


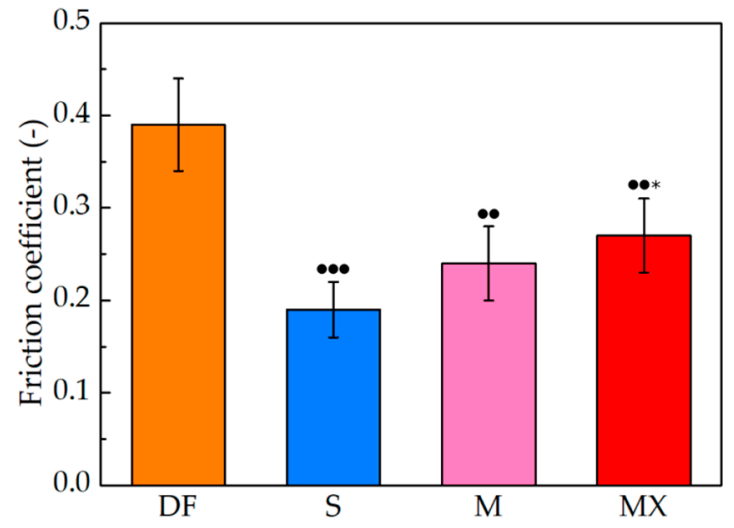

(b)

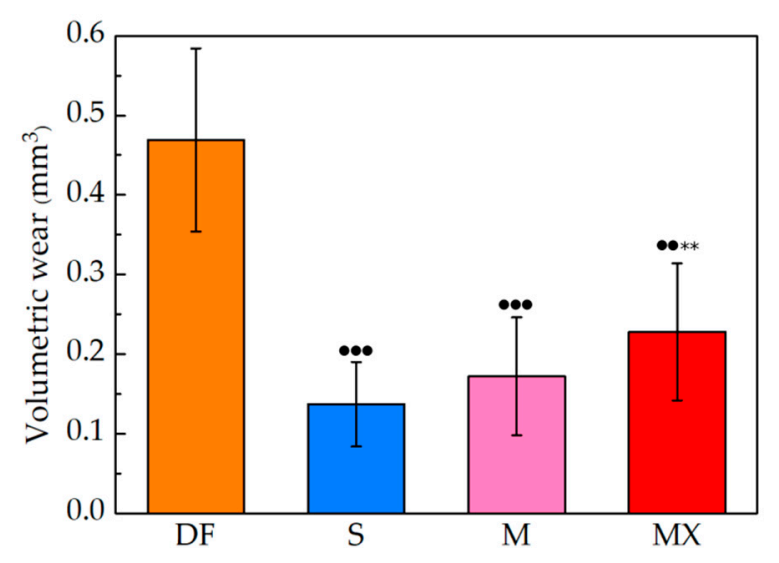

(c)

Figure 3. (a) Friction coefficients in function of time; (b) friction coefficients in fretting conditions of the friction pair without grease (DF) and in the environment of saliva (S) and its preparations (M and $\mathrm{MX}$ ); and (c) volumetric wear in fretting conditions after one hour of testing. Designations: ${ }^{*} p<0.05$, ${ }^{* *} p<0.01,{ }^{* * *} p<0.001$ in relation to the environment of natural saliva (S); $\bullet<<0.05, \bullet \bullet p<0.01$, $\bullet \bullet<0.001$ in relation to dry friction (DF).

Figure $3 c$ shows the results of volumetric wear loss in the material structure after fretting. Obtained data indicate that all tested lubricants ( $, M, M X)$ have statistically significant lower wear, respectively: $\mathrm{S}(\bullet \bullet p<0.001), \mathrm{M}(\bullet \bullet p<0.001)$, and MX $(\bullet \bullet p<0.01)$ in relation to dry friction (DF). The lowest material loss of the steel sample tested in fretting conditions was obtained for natural saliva $\mathrm{S}\left(\sim 0.14 \mathrm{~mm}^{3}\right)$ and composition $\mathrm{M}\left(\sim 0.17 \mathrm{~mm}^{3}\right)$. Slightly higher wear was noted for preparation MX $\left(\sim 0.23 \mathrm{~mm}^{3}\right)$ and the highest for dry friction $\left(\sim 0.47 \mathrm{~mm}^{3}\right)$. In addition, it was observed that for preparation MX (** $p<0.01)$ a statistically significant higher material wear in relation to natural saliva was observed, which may result from the complex chemical structure of the components of this saliva substitute.

In addition, according to Fouvry's assumption [34], the wear of materials in fretting conditions depends on the energy dissipated in each friction cycle. The amount of energy can be equated with the size of the hysteresis loop. With the increase of its area, dissipated energy grows, and the degree of materials wear is higher. The sample curves obtained during fretting are shown in Figure 4.

The nature of the obtained curves indicates a partial contact with micro-slip. Dissipated energy was the highest in dry friction $\left(E_{\text {diss }}=527 \mu \mathrm{J}\right)$, which is associated with high resistance to motion and increased wear. In the case of other preparations, it can be noticed that the obtained results are similar, especially for substitute $\mathrm{M}\left(E_{\text {diss }}=318 \mu \mathrm{J}\right)$ and natural saliva $\left(E_{\text {diss }}=289 \mu \mathrm{J}\right)$. Taking the above into account, the degree of wear of prosthetic and orthodontic elements made of austenitic steel should be comparable, both in healthy patients and using saliva preparations with the addition of mucins. A slightly larger hysteresis loop appears when using solution MX $\left(E_{\text {diss }}=369 \mu \mathrm{J}\right)$. Trends observed in the dissipated energy values during friction are confirmed by the results of volumetric testing of samples, shown in Figure 3b. According to Fouvry and Kapsa [35], the method of measuring fretting wear based on dissipated energy is the most accurate. This assumption works best during sliding over the entire contact area. Obtained results confirm this relationship, even in the case of slips on the part of the contact area.

From the obtained results, it can be concluded that the presence of a lubricant in the form of mucin or mucin and xanthan gum on the surface of dental metal biomaterials reduces their wear under fretting conditions, similar to typical sliding observed for the pin-on-disc system [36]. 


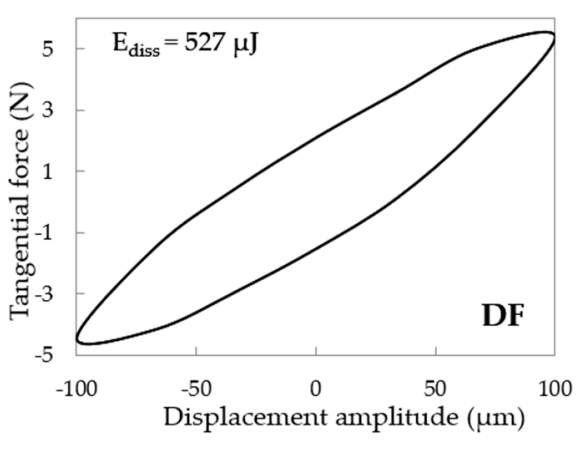

(a)

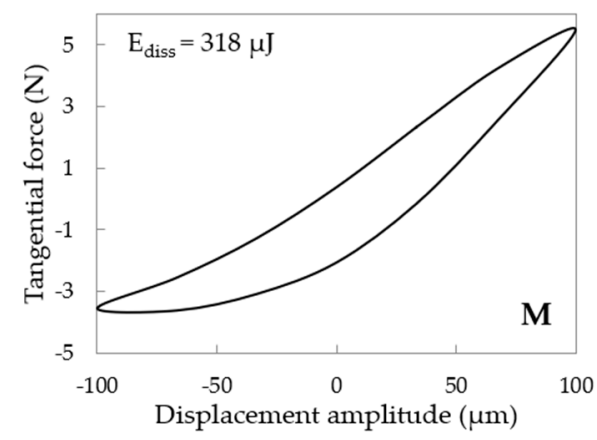

(c)

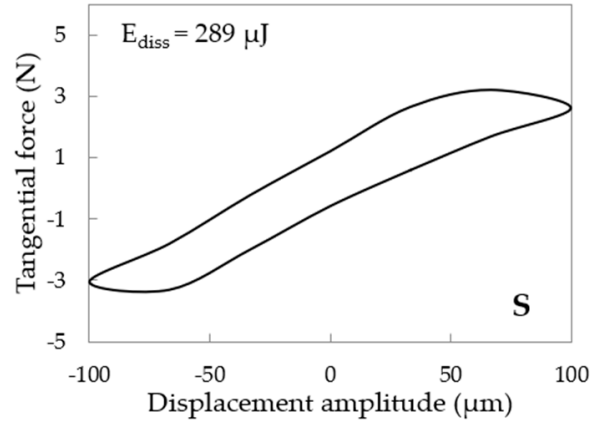

(b)

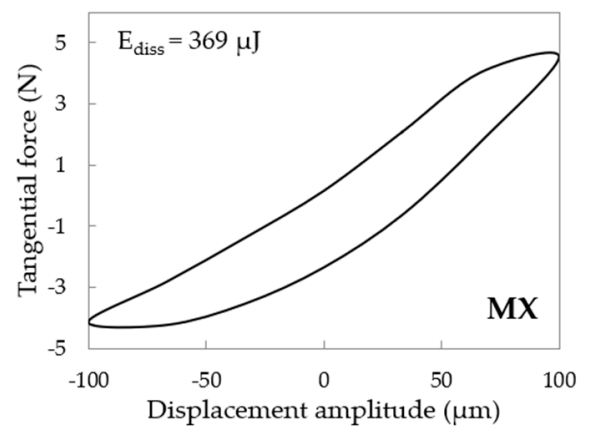

(d)

Figure 4. Energy dissipated during one sliding cycle in fretting conditions in the environment of: (a) Without grease; (b) saliva; (c) mucin-based saliva substitute; and (d) mucin-based saliva substitute with xanthan gum.

The results of microscopic observations of the 316 austenitic steel surface after the fretting process are shown in Figure 5. The view of fretting wear scars is shown in Figure 5a, where significant damage of the steel surface is observed. Various damage phenomenon associated to fretting wear have been observed, as abrasive, fatigue and adhesive. The delamination of the steel surface (Figure $5 b$ ), where individual fragments of the material are gradually breaking away from the surface, resulting in places with removed fragments of material, was observed. Numerous free wear products on the wear scars surface (Figure $5 c$ ) were also noted. The presence of these particles between the friction surfaces results in reduction of their size and in effect formation of agglomerates. The resulting products can additionally promote the abrasive wear mechanism. Figure $5 \mathrm{~d}$ presents the surface of the steel with a visible lubrication layer composed of wear products and saliva environment.

Authors of many works $[11,37,38]$ indicate the effect of fretting on the crack initiation processes in the material. The resulting fatigue cracks increase and damage of the surface causes the formation of wear particles, their further oxidation, and hardening. The presence of these solid particles (size range: Nano to micrometers) between surfaces at the friction interface leads to a reduction in their size and formation of agglomerates. The authors of the work in Reference [10] emphasize that the abrasive properties of these particles can promote the mechanism of abrasive wear. Increasing their amount results in the separation of both surfaces with a layer of oxide particles and determining the conditions of wear. There are also observed processes of transferring materials with intensive oxidation in the friction zone [10]. Fretting wear is conditioned by the coexistence of several processes: Adhesion, fatigue, abrasion, and corrosion. The consequence of fretting is the reduction of durability and shortening the time of operational reliability of medical constructions. 


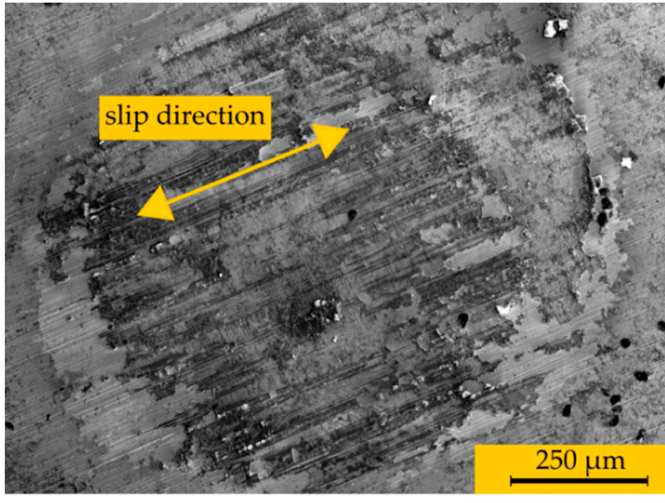

(a)

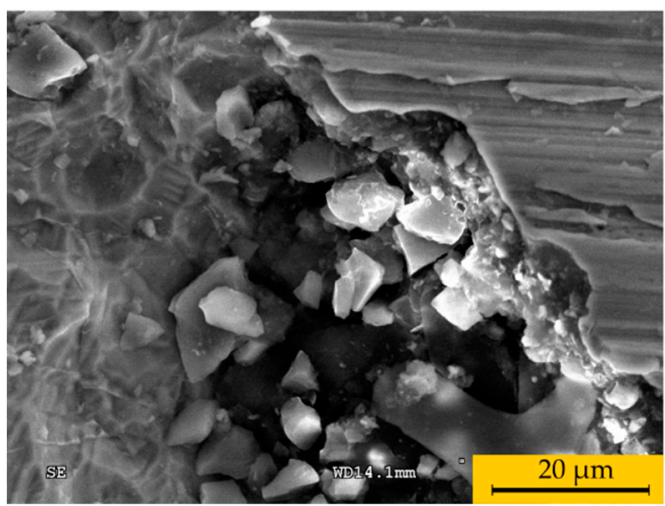

(c)

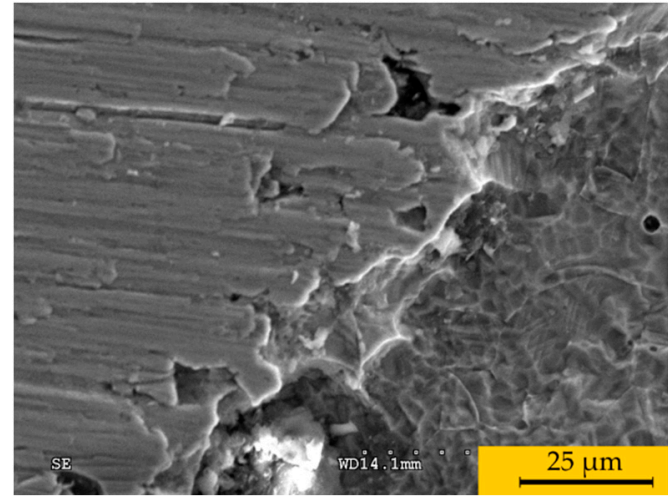

(b)

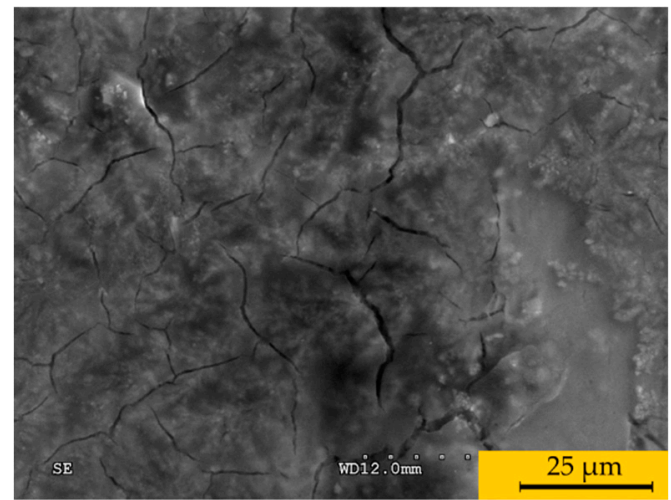

(d)

Figure 5. SEM observations of 316 austenitic stainless steel surface after fretting tests: (a) Fretting wear scars (b) delamination of the sample surface; (c) products of friction wear; and (d) fractures of the lubricating layer.

The fretting process leads to the release and consequent accumulation of metallic impurities in the surrounding tissues and body fluids and the release of metal ions into the body, which may be toxic, cause allergic reactions, elicit an immune response, and initiate tissue inflammation [39]. It is also observed loosening the implant placement, which ultimately leads to damage to the entire structure [10,39]. According to Zhang [38], 57\% of dental implants start to be unstable already in the first year, 30\% in the second year, and 5\% in the third year of use. In several research groups [40-42], tribocorrosion tests are conducted using stainless steel, alloys: CP-Ti, Ti-6Al-4V, and Co-Cr-Mo in the environment of body fluids, including artificial saliva [10,43,44].

Using the scanning electron microscope equipped with an EDS attachment for X-ray microanalysis, the chemical composition of the surface of tested material samples after friction tests in fretting conditions was performed. Figure 6a presents the view of fretting wear scars with the indication of two selected elements included in 316 steel: Oxygen and chromium.

The analysis of the chemical composition of the 316 steel surface after fretting friction (Figure $6 \mathrm{~b}$ ) shows that oxide layers were formed in the friction zone, which is particularly visible for friction without lubricant (the process carried out with free access of oxygen from the environment) and friction in the natural saliva. Increased oxygen concentration in the friction zone could be caused by the fact that the presence of numerous wear products which, acting as abrasive, led to: (1) increase of temperature in the friction zone and (2) uncovering subsequent layers of metal biomaterial (by cutting off fragments of material and their partial transport outside the friction zone) and access of oxygen 
(especially under dry friction conditions), which in turn promotes the formation of tightly adherent layers of chromium oxides, according to the following equation:

$$
2 \mathrm{Cr}+{ }^{3} /{ }_{2} \mathrm{O}_{2}=\mathrm{Cr}_{2} \mathrm{O}_{3}
$$

The $\mathrm{Cr}^{2+}$ cations have strong reducing properties, both in aqueous and solid phase solutions, easily oxidizing to $\mathrm{Cr}^{3+}$ ions, e.g.,

$$
\begin{aligned}
2 \mathrm{Cr}^{2+}+{ }^{1} /{ }_{2} \mathrm{O}_{2}+\mathrm{H}_{2} \mathrm{O} & =2 \mathrm{Cr}^{3+}+2 \mathrm{OH}^{-} \\
2 \mathrm{CrO}+{ }^{1} /{ }_{2} \mathrm{O}_{2} & =\mathrm{Cr}_{2} \mathrm{O}_{3}
\end{aligned}
$$

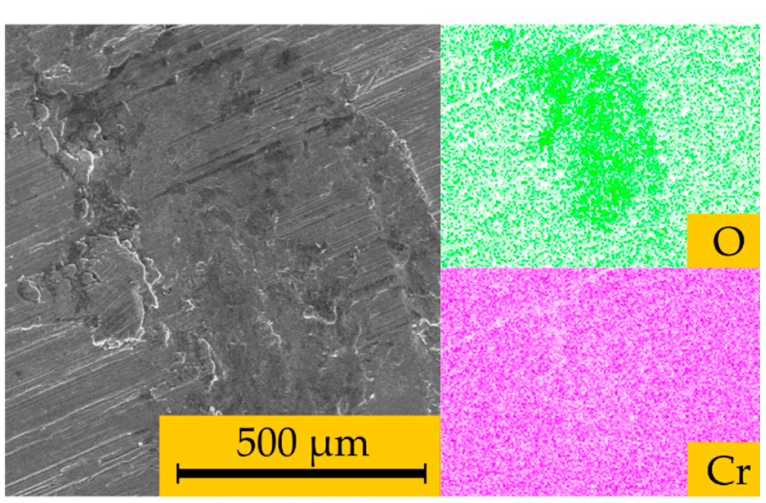

(a)

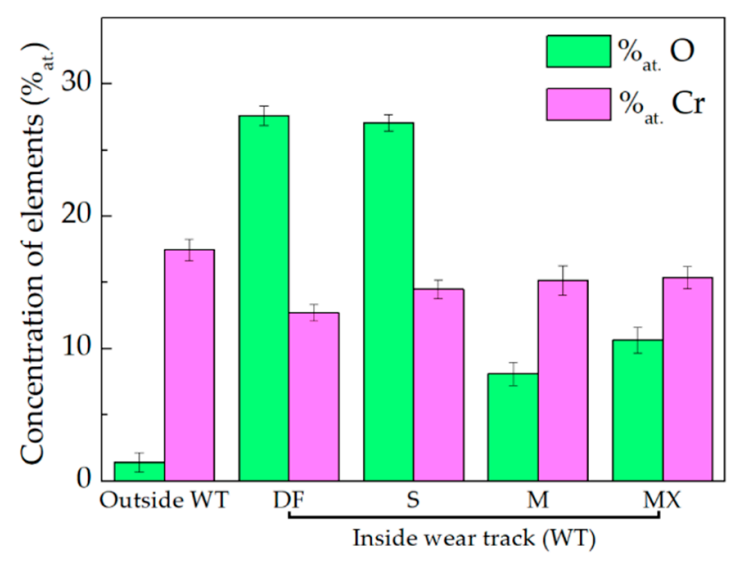

(b)

Figure 6. EDS analysis of the sample surface after friction test: (a) An exemplary distribution of oxygen and chromium on the sample surface $(\mathbf{b})$ concentration of oxygen and chromium on the friction surface.

The analysis of the atomic composition of oxygen and chromium elements on the surface of the tested austenitic steel suggests that, under fretting conditions, more or less stable chromium oxides may be formed at the frictional location. The amount of oxygen in this place is higher than beyond the trace of friction. The proportions of the amount of chromium and oxygen can suggest the presence of oxides such as $\mathrm{CrO}, \mathrm{CrO}_{2}$, and $\mathrm{Cr}_{2} \mathrm{O}_{3}$ in the place of friction on the surface of the biomaterial, responsible for the formation of a passive film, which has anticorrosion protection [45]. A more complex chromium compound may also be present, but the measurement capabilities of the device used do not allow for unambiguous identification.

\subsection{Fretting-Corrosion}

Fretting-corrosion tests were carried out in the environment of saliva and its preparations in accordance with the previously described methodology. The recorded curves of potential changes (Figure 7$)$ in the open circuit $\left(E_{O C P}\right)$ allowed performing a preliminary assessment of corrosion resistance of samples. 


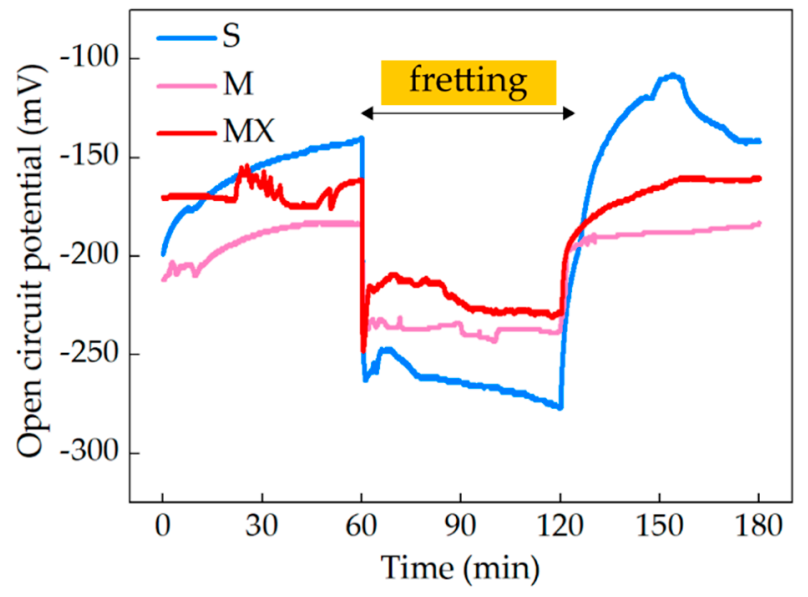

Figure 7. Open Circuit Potential $\left(E_{O C P}\right)$ during the fretting test in different environments of saliva and its preparations.

The obtained data show that, in the first stage of the test, the $E_{O C P}$ increased and then stabilized. This may be related to the formation of a passive layer that increases the corrosion resistance of the samples. Due to friction, this layer is removed and the active surface of the metal is exposed. It leads to a significant decrease in the potential value, and thus a decrease in the corrosion resistance of steel in the tested saliva preparations. This confirms literature data $[3,10]$ on the intensification of corrosion processes during fretting, resulting mainly from surface depassivation [41]. Potential difference $\left(\triangle E_{O C P}\right)$ between rest potential and potential during fretting are shown in Table 2.

Table 2. Difference between rest potential and potential during fretting.

\begin{tabular}{cc}
\hline Preparation & $\Delta \boldsymbol{E}_{\boldsymbol{O C P}}(\mathrm{mV})$ \\
\hline $\mathrm{S}$ & $125 \pm 21$ \\
$\mathrm{M}$ & $57 \pm 7$ \\
$\mathrm{MX}$ & $63 \pm 11$ \\
\hline \multicolumn{3}{c}{ \pm SD. }
\end{tabular}

The highest potential changes are observed for natural saliva (S), which may indicate its high reactivity in contact with steel. This is not a beneficial phenomenon, especially in the aspect of tribocorrosion. After the friction stopped, the resting potentials began to increase, but the time required for their stabilization was varied and depended on the environment. In the case of highly reactive natural saliva, it was relatively long compared to artificial saliva $(M, M X)$ preparations. It could be determined by their chemical composition. High concentration of organic components in the formulations increases their potential for forming an adsorption layer that stabilizes $E_{O C P}$. The increased rate of stabilization of the M preparation in relation to MX may, however, result from the high viscosity and viscoelasticity given by the xanthan gum, and thus the macromolecules have a difficult access to the steel surface.

The increase in potentials indicates the reconstruction of the passive layer, the quality of which can significantly affect the corrosion resistance of steel in static conditions. After the preliminary tests, basic tests of changes in the current intensity at a variable potential (potentiodynamic method) were carried out, the results of which are shown in Figure 8. Particular attention was paid to the values of corrosion potentials and polarizations (Table 3). 


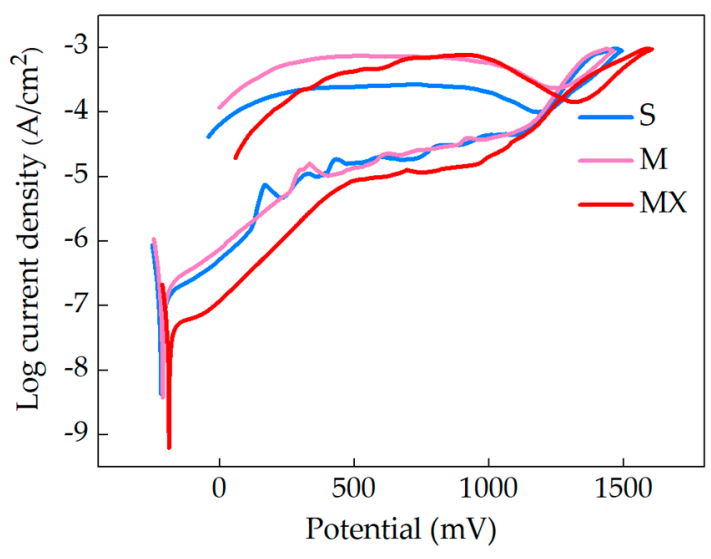

(a)

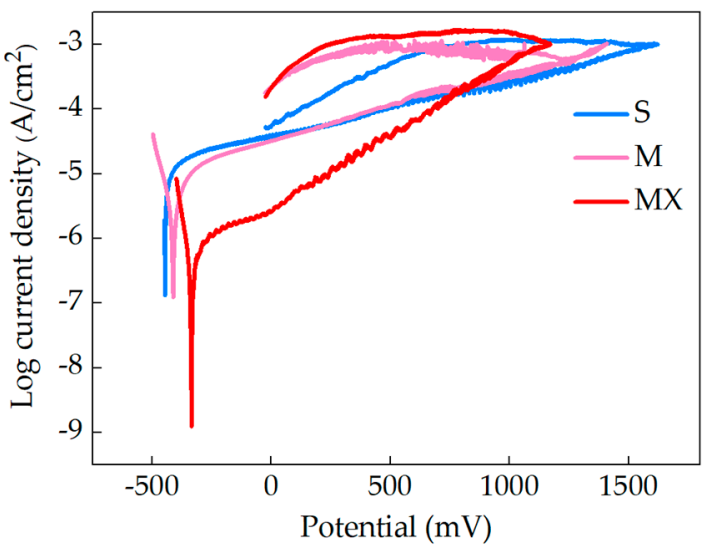

(b)

Figure 8. Potentiodynamic tests in the environment of saliva and its preparations: (a) Without fretting; and (b) during fretting.

The course of the hysteresis loop suggests that austenitic steel is a material susceptible to corrosion, especially in fretting conditions, where the transpasivation of the surface of the samples did not occur. This is confirmed by the images obtained during microscopic observations (Figure 9). The comparison of corrosive environments shows that the MX solution showed the most advantageous electrochemical characteristics, which may be associated with an increased amount of organic compounds (mucin + xanthan gum), improving the quality of the adsorptive film. The solution $\mathrm{M}$, based only on mucin, showed parameters similar to natural saliva.

Table 3. Corrosion potential $\left(E_{c o r}\right)$ and polarization resistance $\left(R_{p}\right)$ in saliva and mucin-based saliva substitutes.

\begin{tabular}{|c|c|c|c|c|}
\hline \multirow{2}{*}{ Preparation } & \multicolumn{2}{|c|}{ Corrosion } & \multicolumn{2}{|c|}{ Fretting-Corrosion } \\
\hline & $E_{c o r}(\mathrm{mV})$ & $R_{p}\left(\mathrm{k} \Omega \cdot \mathrm{cm}^{2}\right)$ & $E_{c o r}(\mathrm{mV})$ & $R_{p}\left(\mathrm{k} \Omega \cdot \mathrm{cm}^{2}\right)$ \\
\hline S & -214 & 146.02 & -446 & 6.24 \\
\hline M & -209 & 104.75 & -418 & 5.78 \\
\hline $\mathrm{MX}$ & -189 & 345.93 & -340 & 35.94 \\
\hline
\end{tabular}

The test results indicate a significant effect of friction on the intensification of corrosion. Relatively high values of polarization resistance of the samples under static conditions indicate the presence of an oxide-organic layer adsorbed on the surface of the steel, which to some extent inhibits the flow of electrons and protects against access of oxygen and water. During friction, this layer is destroyed and the active metal surface partially exposed leads to a reduction of the polarization resistance, displacement of corrosion potentials in the negative direction, and thus the acceleration of corrosion processes. This is clearly visible on the registered anodic polarization curves (Figure 8), whose characteristic irregular course in the positive potential range may indicate the damage and renewal of the passive layer (Figure 8b). 


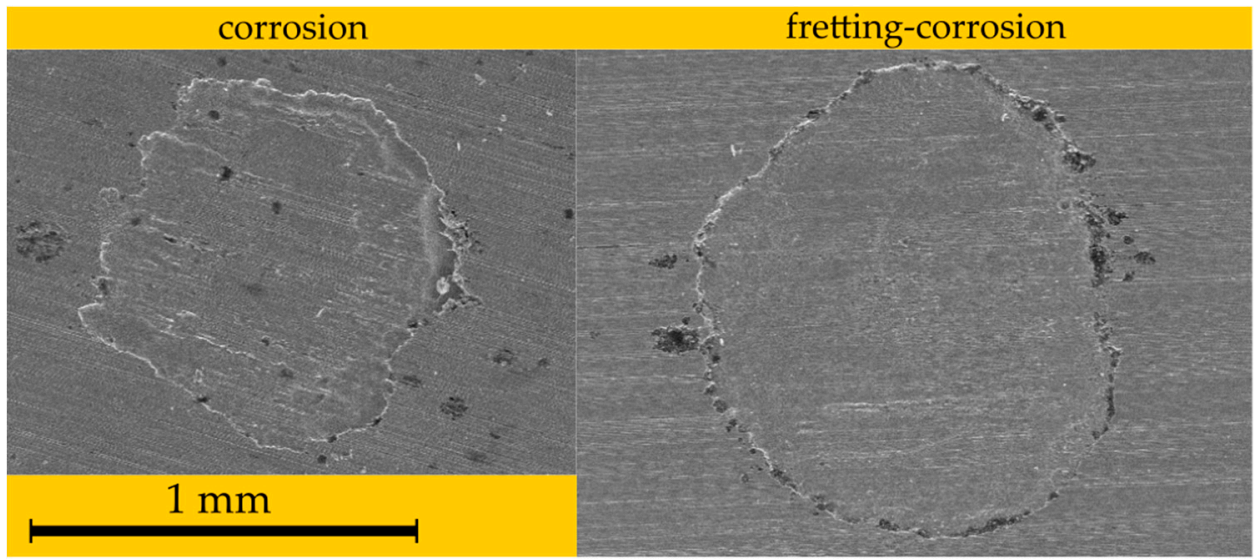

(a)

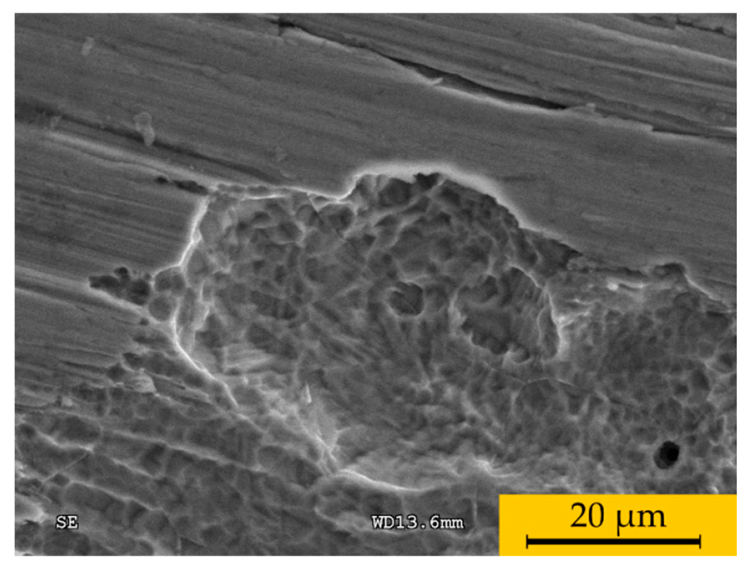

(b)

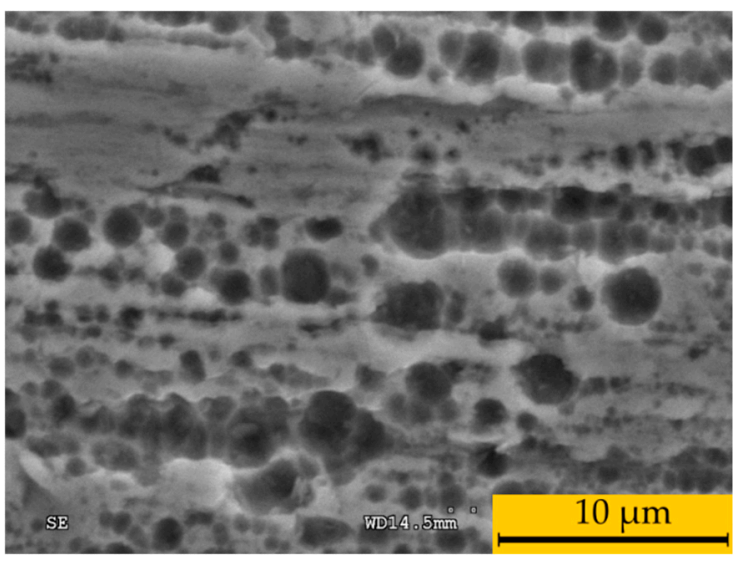

(c)

Figure 9. SEM observations after corrosion and fretting-corrosion potentiodynamic tests: (a) Comparison of traces of sample contact with counter-sample after corrosion and fretting-corrosion tests; (b) boundary of fretting wear scars; and (c) corrosion pits.

In the work of Holmes et al. [45], it has been proven that at higher loads during friction the concentration of the resulting products of wear occurs, which allows the creation of so-called tribofilm protecting the surface from wear. On the other hand, an increase in the density of the corrosive current in these places has been observed, which is not a beneficial phenomenon. Corrosion processes can cause toxic and allergic reactions in the human body, inflammation, and cancer development $[46,47]$. In the oral cavity, metals are constantly in contact with saliva, favoring the development of electrochemical corrosion. In addition, metal ions released during corrosion from metal dental constructions can enter the gastrointestinal tract and accumulate in the stomach, liver, kidneys, spleen, bones, lungs, brain, or mucosa. Numerous studies $[4,48]$ indicate the importance of corrosion resistance of biomaterials in the oral environment. The results of such tests should be used in the development of chemical compositions of alloys for dentistry and saliva substitutes [49,50].

Observations given by scanning electron microscopy (SEM) (Figure 9) clearly indicate the intensification of corrosion processes during fretting. The traces of the sample contact with the counter-sample are noticeably larger and deeper after fretting and fretting-corrosion tests (Figure 9a). Numerous corrosion pits are also noticeable, particularly at the contact edge (Figure $9 \mathrm{~b}$ ) and beyond the trace of contact/friction (Figure 9c). 
Microscopic analysis using CLSM method (Figure 10) shows that austenitic steel is susceptible to corrosion process under fretting conditions. Both during the corrosion and fretting-corrosion tests, the highest loss of material was observed at the edges of the kinematic pair contact, which may indicate crevice corrosion. However, during fretting-corrosion processes, wear was more uniform (probably due to oscillating motion) than during corrosion itself, where pits are focused on selected areas.

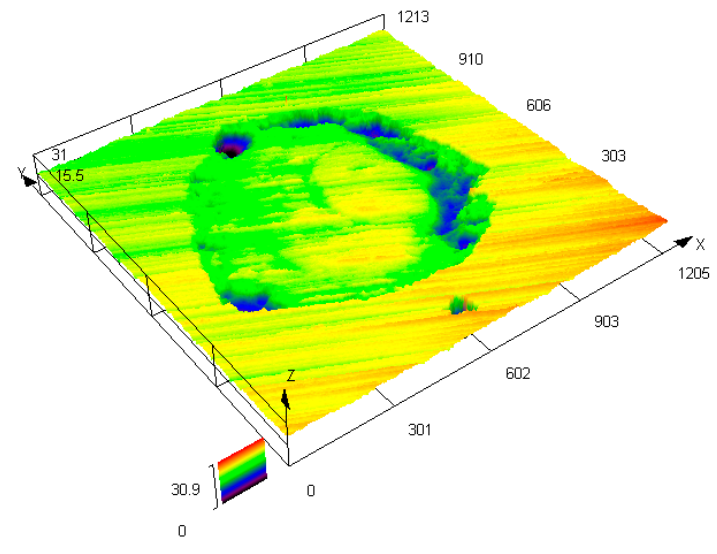

(a)

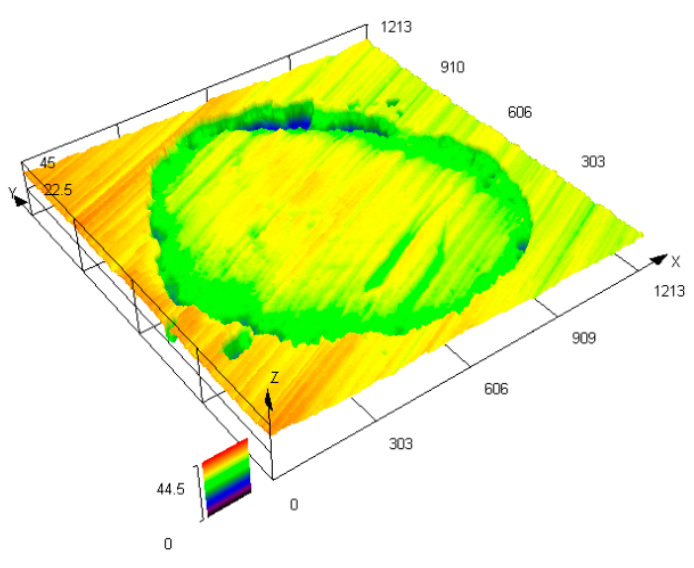

(b)

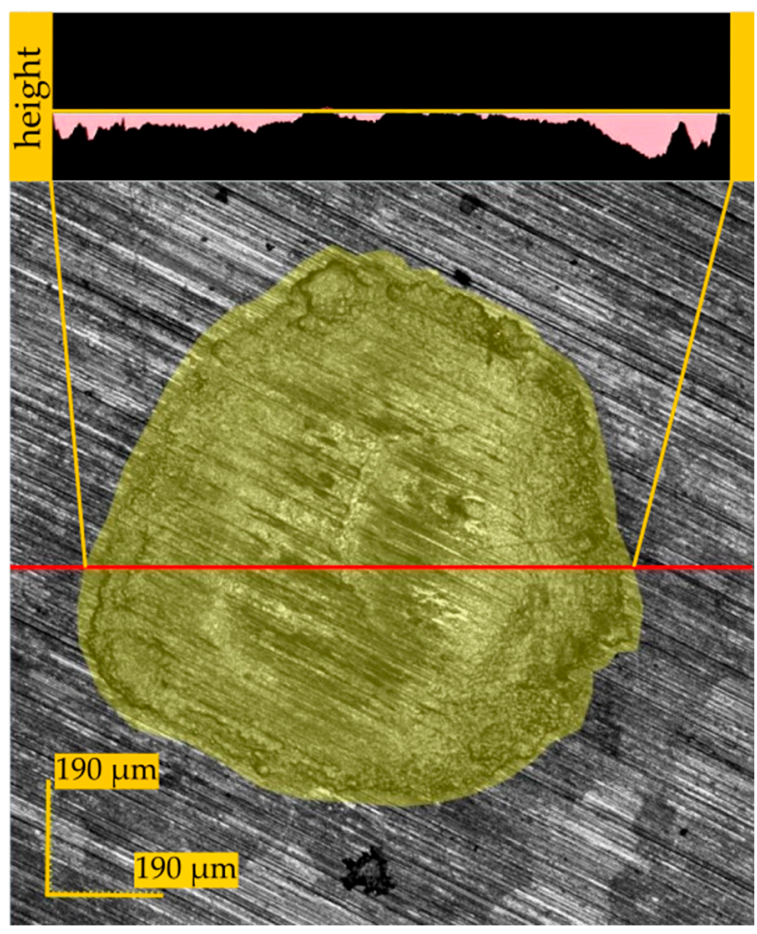

(c)

Figure 10. CLSM observations of sample surface after fretting-corrosion tests: (a) Trace after corrosion test; (b) trace after the fretting-corrosion test; and (c) scheme of determining the volume wear on a confocal laser scanning microscope.

Based on the obtained results, a schematic model of observed fretting-corrosion processes was proposed (Figure 11). In the area of sample contact with the counter-sample, there is an adsorbed viscoelastic mucin layer. Its role is to reduce the resistance to movement and reduce wear. However, the high viscosity of mucin may cause the formation of an abrasive layer and in effect leads to secondary wear. This area is depleted of oxygen, whereby the contact layer of material becomes an anode, where the oxidation process occurs. The area beyond the friction has a higher oxygen concentration, which makes it a cathode and occurs in the reduction process. Similar observations were observed in works $[39,41]$. The potential difference leads to the formation of corrosion pits on the edge of the trace of friction. In addition, ions, such as chlorine, can enter the contact zone of the saliva solution, which can intensify the corrosion process. 


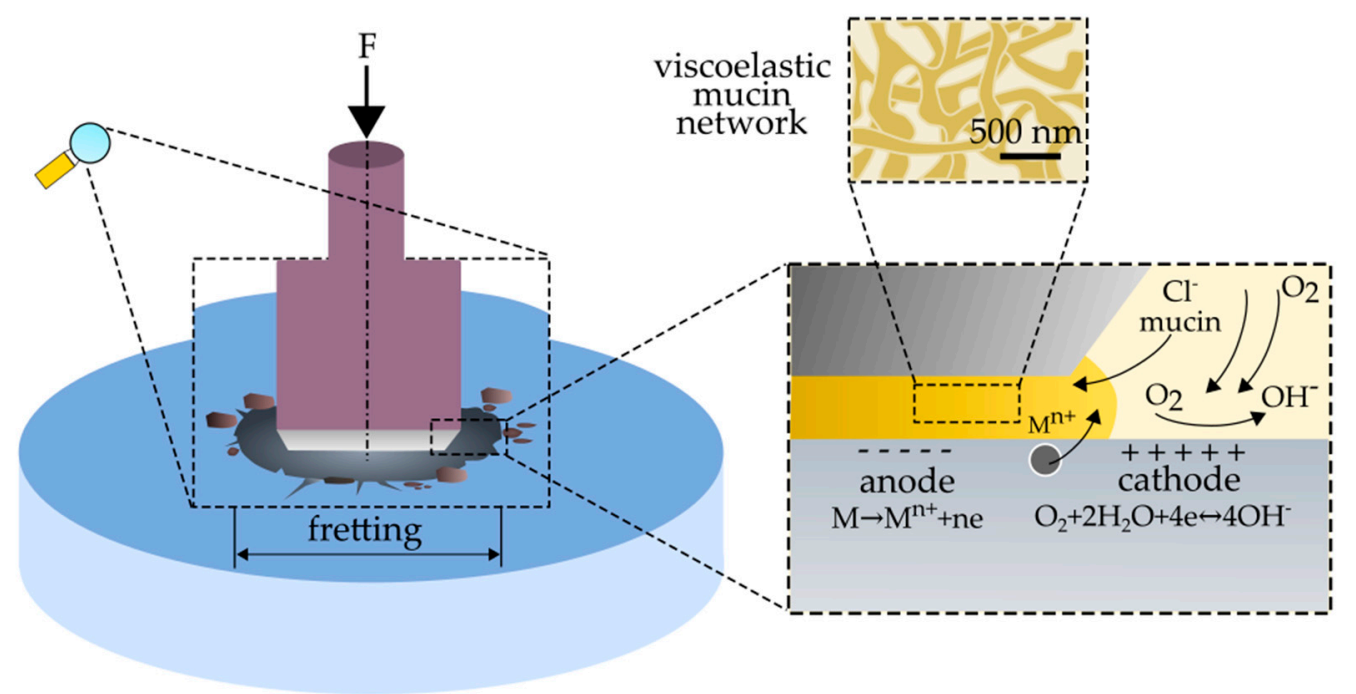

Figure 11. Scheme of fretting-corrosion processes in the environment of saliva and its preparations.

\section{Conclusions}

Tribological and electrochemical techniques combined with optical and electron microscopy have been used to identify the mechanism of austenitic steel degradation, under fretting conditions in the presence of saliva and its substitutes. Performed studies leads to the following conclusions:

- fretting processes lead to an intensification of the corrosive wear of austenitic steel. The mechanism of corrosion failure in fretting conditions is similar to crevice corrosion and is based on gradients of oxygen concentration at the friction location.

- the presence of organic components (mucin, xanthan gum) in the preparation of artificial saliva accelerates and improves the quality of the adsorptive layer formed on the steel surface. The formed layer, in static conditions, protects the material against corrosion.

- the xanthan gum in the saliva preparation can lead to an intensification of the secondary wear of steel, which is related to the difficult removal of wear products from the friction area.

- the proposed compositions of artificial saliva have favorable rheological, tribological, and electrochemical properties, and can be used by people that have problems with the secretion of natural saliva.

In the work, it was shown that fretting and fretting-corrosion processes of 316 austenitic stainless steel depend on saliva composition.

Author Contributions: J.M. conceived the concept for this paper and wrote the original version of the manuscript. J.M., D.Ł. and M.K. performed an experimental part. J.M., D.Ł. and M.K. collected and analyzed data from the available literature, and contributed to the writing of this paper.

Funding: Studies were conducted within the framework of study No. 2015/N/ST8/03025 and financed with funds for science from the National Science Centre, Poland. This scientific work was realized in frame of work, No. S/WM/2/2017 and financed from research funds of Ministry of Science and Higher Education, Poland.

Conflicts of Interest: The authors declare no conflict of interest.

\section{References}

1. Park, J.; Lakes, R.S. Biomaterials: An introduction, 3rd ed.; Springer: New York, NY, USA, 2007.

2. Chen, Q.Z.; Thouas, G.A. Metallic implant biomaterials. Mater. Sci. Eng. R Rep. 2015, 87, 1-57. [CrossRef]

3. Dabrowski, J.R.; Klekotka, M.; Sidun, J. Fretting and fretting corrosion of 316L implantation steel in oral cavity environment. Maint. Reliab. 2014, 16, 441-446. 
4. Mystkowska, J.; Ferreira, J.A.; Leszczyńska, K.; Chmielewska, S.; Dąbrowski, J.R.; Wieciński, P.; Kurzydłowski, K.J. Biocorrosion of 316LV steel used in oral cavity due to Desulfotomaculum nigrificans bacteria. J. Biomed. Mater. Res. Part B Appl. Biomater. 2017, 105, 222-229. [CrossRef] [PubMed]

5. Mystkowska, J.; Niemirowicz-Laskowska, K.; Łysik, D.; Tokajuk, G.; Dabrowski, J.R.; Bucki, R. The Role of Oral Cavity Biofilm on Metallic Biomaterial Surface Destruction-Corrosion and Friction Aspects. Int. J. Mol. Sci. 2018, 19, 743. [CrossRef] [PubMed]

6. Andrysewicz, E.; Mystkowska, J.; Dąbrowski, J.R.; Olchowik, R. Influence of self-made saliva substitutes on tribological characteristics of human enamel. Acta Bioeng. Biomech. 2014, 16, 67-74. [PubMed]

7. Duisabeau, L.; Combrade, P.; Forest, B. Environmental effect on fretting of metallic materials for orthopaedic implants. Wear 2004, 256, 805-816. [CrossRef]

8. Geringer, J.; Forest, B.; Combrade, B. Fretting-corrosion of materials used as orthopedic implants. Wear 2005, 259, 943-951. [CrossRef]

9. Vadiraj, A.; Kamaraj, M. Effect of surface treatments on fretting fatigue damage of biomedical titanium alloys. Tribol. Int. 2007, 40, 82-88. [CrossRef]

10. Sivakumar, B.; Kumar, S.; Sankara Narayanan, T.S.N. Fretting corrosion behaviour of Ti-6Al-4V alloy in artificial saliva containing varying concentrations of fluoride ions. Wear 2011, 270, 317-324. [CrossRef]

11. Souza, J.C.M.; Barbosa, S.L.; Ariza, E.; Celis, J.P.; Rocha, L.A. Simultaneous degradation by corrosion and wear of titanium in artificial saliva containing fluorides. Wear 2012, 292-293, 82-88. [CrossRef]

12. Močnik, P.; Kosec, T.; Kovač, J.; Bizjak, M. The effect of $\mathrm{pH}$, fluoride and tribocorrosion on the surface properties of dental wires. Mater. Sci. Eng. C 2017, 78, 682-689. [CrossRef] [PubMed]

13. Andrysewicz, E.; Mystkowska, J.; Kolmas, J.; Jalbrzykowski, M.; Olchowik, R.; Dabrowski, J.R. Influence of artificial saliva compositions on tribological characteristics of Ti-6Al-4V implant alloy. Acta Bioeng. Biomech. 2012, 14, 71-79. [PubMed]

14. Ranjitkar, S.; Kaidonis, J.A.; Towsend, G.C.; Richards, L.C. An in vitro assessment of the effect of load and $\mathrm{pH}$ on wear between opposing enamel and dentin surfaces. Arch. Oral Biol. 2008, 53, 1011-1016. [CrossRef] [PubMed]

15. Mystkowska, J.; Car, H.; Dąbrowski, J.R.; Romanowska, J.; Klekotka, M.; Milewska, A.J. Artificial mucin-based saliva preparations-Physicochemical and tribological properties. Oral Health Prev. Dent. 2018, 16, 183-193.

16. Yakubov, G.E.; Macakova, L.; Wilson, S.; Windust, J.H.C.; Stokes, J.R. Aqueous lubrication by fractionated salivary proteins: Synergistic interaction of mucin polymer brush with low molecular weight macromolecules. Tribol. Int. 2015, 89, 34-45. [CrossRef]

17. Glantz, P.O. Interfacial phenomena in the oral cavity. Colloids Surf. A Physicochem. Eng. Asp. 1997, 123-124, 657-670. [CrossRef]

18. Bansil, R.; Turner, B.S. Mucin structure, aggregation, physiological functions and biomedical applications. Curr. Opin. Colloid Interface Sci. 2006, 11, 164-170. [CrossRef]

19. Hannig, C.; Hannig, M.; Kensche, A.; Carpenter, G. The mucosal pellicle? An underestimated factor in oral physiology. Arch. Oral Biol. 2017, 80, 144-152. [CrossRef]

20. Mystkowska, J.; Karalus, W.; Sidorenko, J.; Dąbrowski, J.R.; Kalska-Szostko, B. Biotribological properties of dentures lubricated with artificial saliva. J. Frict. Wear 2016, 37, 544-551. [CrossRef]

21. Saleh, J.; Figueiredo, M.A.; Cherubini, K.; Salum, F.G. Salivary hypofunction: An update on aetiology, diagnosis and therapeutics. Arch. Oral Biol. 2015, 60, 242-255. [CrossRef]

22. Hahnel, S.; Rosentritt, M.; Handel, G.; Burgers, R. Influence of saliva substitute films on initial Streptococcus mutans adhesion to enamel and dental plaque. J. Dent. 2008, 36, 977-983. [CrossRef] [PubMed]

23. Choi, H.; Mitchell, J.R.; Gaddipati, S.R.; Hill, S.E.; Wolf, B. Shear rheology and filament stretching behavior of xanthan gum and carboxymethyl cellulose solution in presence of saliva. Food Hydrocoll. 2014, 40, 71-75. [CrossRef] [PubMed]

24. Fathi, M.H.; Salehi, M.; Saatchi, A.; Mortazavi, V.; Moosavi, S.B. In vitro corrosion behavior of bioceramic, metallic, and bioceramic-metallic coated stainless steel dental implants. Dent. Mater. 2003, 19, 188-198. [CrossRef]

25. Sharifnabi, A.; Fathi, M.H.; Eftekhari Yekta, B.; Hossainalipour, M. The structural and bio-corrosion barrier performance of Mg-substituted fluorapatite coating on 3161 stainless steel human body implant. Appl. Surf. Sci. 2014, 288, 331-340. [CrossRef] 
26. Harvey, N.M.; Yakubov, G.E.; Stokes, J.R.; Klein, J. Lubrication and load-bearing properties of human salivary pellicles adsorbed ex vivo on molecularly smooth substrata. Biofouling 2012, 28, 843-856. [CrossRef] [PubMed]

27. Celli, J.; Gregor, B.; Turner, B.; Afdhal, N.H.; Bansil, R.; Erramilli, S. Viscoelastic properties and dynamics of porcine gastric mucin. Biomacromolecules 2005, 6, 1329-1333. [CrossRef] [PubMed]

28. Heintze, S.D. How to qualify and validate wear simulation devices and methods. Dent. Mater. 2006, 22, 712-734. [CrossRef]

29. Sidun, J.; Dabrowski, J.R. The method of fretting wear assessment with the application of 3D laser measuring microscope. In Advances in Intelligent Systems and Computing; Gzik, M., Tkacz, E., Paszenda, Z., Pietka, E., Eds.; Springer: Switzerland, Poland, 2018; pp. 369-377, 2194-5357.

30. Nosonovsky, M.; Bhushan, B. Multiscale friction mechanisms and hierarchical surfaces in nano- and bio-tribology. Mater. Sci. Eng. R Rep. 2007, 58, 162-193. [CrossRef]

31. Bansil, R.; Stanley, E.; LaMont, J.T. Mucin biophysics. Annu. Rev. Physiol. 1995, 57, 635-657. [CrossRef]

32. Chen, D.T.N.; Wen, Q.; Janmey, P.A.; Crocker, J.; Yodh, A.G. Rheology of Soft Materials. Annu. Rev. Condens. Matter Phys. 2010, 1, 301-322. [CrossRef]

33. Wagner, N.J.; Brady, J.F. Shear thickening in colloidal dispersions. Phys. Today 2009, 62, 27-32. [CrossRef]

34. Fouvry, S.; Kapsa, P.; Vincent, L. Quantification of fretting damage. Wear 1996, 200, 186-205. [CrossRef]

35. Fouvry, S.; Kapsa, P. An energy description of hard coating wear mechanisms. Surf. Coat. Technol. 2001, 138, 141-148. [CrossRef]

36. Mystkowska, J.; Jałbrzykowski, M.; Dabrowski, J.R. Tribological properties of selected self-made solutions of synthetic saliva. Solid State Phenom. 2013, 199, 567-572. [CrossRef]

37. Zhu, M.H.; Zhou, Z.R. On the mechanisms of various fretting wear modes. Tribol. Int. 2011, 44, 1378-1388. [CrossRef]

38. Zhang, B.; Cai, Z.; Gan, X.; Zhu, M.; Yu, H. Dual motion fretting wear behaviors of titanium and its alloy in artificial saliva. Trans. Nonferrous Met. Soc. China 2014, 24, 100-107. [CrossRef]

39. Licausi, M.P.; Munoz, A.I.; Borras, V.A. Influence of the fabrication process and fluoride content on the tribocorrosion behaviour of Ti6Al4V biomedical alloy in artificial saliva. J. Mech. Behav. Biomed. Mater. 2013, 20, 137-148. [CrossRef]

40. Revathi, A.; Borrás, A.D.; Muñoz, A.I.; Richard, C.; Manivasagam, G. Degradation mechanisms and future challenges of titanium and its alloys for dental implant applications in oral environment. Mater. Sci. Eng. C 2017, 76, 1354-1368. [CrossRef]

41. Vieira, A.C.; Ribeiro, A.R.; Rocha, L.A.; Celis, J.P. Influence of $\mathrm{pH}$ and corrosion inhibitors on the tribocorrosion of titanium in artificial saliva. Wear 2006, 261, 994-1001. [CrossRef]

42. Mroczkowski, M.L.; Hertzler, J.S.; Humphrey, S.M.; Johnson, T.; Blanchard, C.R. Effect of impact assembly on the fretting corrosion of modular hip tapers. J. Orthop. Res. 2006, 24, 271-279. [CrossRef]

43. Khan, M.A.; Williams, R.L.; Williams, D.F. The corrosion behavior of Ti-6Al-4V, Ti-6Al-7Nb and Ti-13Nb-13Zr in protein solutions. Biomaterials 1999, 20, 631-637. [CrossRef]

44. Buciumeanu, M.; Bagheri, A.; Souza, J.C.M.; Silva, F.S.; Henriques, B. Tribocorrosion behavior of hot pressed CoCrMo alloys in artificial saliva. Tribol. Int. 2016, 97, 423-430. [CrossRef]

45. Holmes, D.; Sharifi, S.; Stack, M.M. Tribo-corrosion of steel in artificial saliva. Tribol. Int. 2014, 75, 80-86. [CrossRef]

46. Schipper, R.G.; Silletti, E.; Vingerhoeds, M.H. Saliva as research material: Biochemical, physicochemical and practical aspects. Arch. Oral Biol. 2007, 52, 1114-1135. [CrossRef] [PubMed]

47. Chiappin, S.; Antonelli, G.; Gatti, R.; De Palo, E.F. Saliva specimen: A new laboratory tool for diagnostic and basic investigation. Clin. Chim. Acta 2007, 383, 30-40. [CrossRef] [PubMed]

48. Lata, S.; Sharma, C.H.; Singh, A.K. Microbial corrosion by thermophilic bacteria. Cent. Eur. J. Eng. 2012, 2, 113-122.

49. Pawlak, Z.; Urbaniak, W.; Oloyede, A. The relationship between friction and wettability in aqueous environment. Wear 2011, 271, 1745-1749. [CrossRef]

50. Liu, S.Y.; Han, Y.; Yin, L.P.; Long, L.; Liu, R. Toxicology studies of a superparamagnetic iron oxide nanoparticles in vivo. Adv. Mat. Res. 2008, 47, 1097-1100. [CrossRef]

(C) 2019 by the authors. Licensee MDPI, Basel, Switzerland. This article is an open access article distributed under the terms and conditions of the Creative Commons Attribution (CC BY) license (http:/ / creativecommons.org/licenses/by/4.0/). 